\title{
Review
}

Obesity and Metabolic Syndrome

Diabetes Metab J 2019;43:744-751

https://doi.org/10.4093/dmj.2019.0175

pISSN 2233-6079 · eISSN 2233-6087

DIABET\&S \& METABOLISM JOURNAL

\section{Adult Stem Cells: Beyond Regenerative Tool, More as a Bio-Marker in Obesity and Diabetes}

\author{
Sabyasachi Sen \\ Division of Endocrinology, Department of Medicine, The George Washington University, Washington, DC, USA
}

Obesity, diabetes, and cardiovascular diseases are increasing rapidly worldwide and it is therefore important to know the effect of exercise and medications for diabetes and obesity on adult stem cells. Adult stem cells play a major role in remodeling and tissue regeneration. In this review we will focus mainly on two adult stem/progenitor cells such as endothelial progenitor cells and mesenchymal stromal cells in relation to aerobic exercise and diabetes medications, both of which can alter the course of regeneration and tissue remodelling. These two adult precursor and stem cells are easily obtained from peripheral blood or adipose tissue depots, as the case may be and are precursors to endothelium and mesenchymal tissue (fat, bone, muscle, and cartilage). They both are key players in maintenance of cardiovascular and metabolic homeostasis and can act also as useful biomarkers.

Keywords: Diabetes mellitus, type 2; Hematopoietic stem cells; Mesenchymal stem cells; Obesity

\section{INTRODUCTION}

At present obesity, diabetes, hypertension, stroke, and coronary artery diseases (CAD) are rising dangerously worldwide. According to National Institute of Diabetes and Digestive and Kidney Diseases (NIDDK, Bethesda, MD, USA), one in three adults are obese and two in every three adults are overweight and obese [1]. World Health Organization estimated 422 billion people are suffering from diabetes [2]. Centers for Disease Control and Prevention (CDC, Atlanta, GA, USA) also anticipates that one out of three adults suffer from hypertension.

One out of every 20 deaths are due to stroke and one out of every four deaths are due to CAD in USA [3-5]. According to CDC 84 million Americans also have prediabetes [6], a condition associated with increased risk of type 2 diabetes mellitus (T2DM), cardiovascular disease (CVD) which includes hypertension, CAD and stroke. In addition to morbidity and mortality these health conditions are associated with a large economic burden. CDC estimates that annual medical cost of obesity in the United States was $\$ 147$ billion dollars [1]. The American
Diabetes Association (ADA) reported that it costs $\$ 245$ billion dollars to treat diabetes and related complications in the United States [7]. According to CDC, approximately $\$ 46$ billion was used to treat hypertension, $\$ 34$ billion for stroke and $\$ 200$ billion for heart disease [3-5].

Diabetes medications and non-pharmaceutical approach such as exercise has shown to be effective in decreasing the cardiovascular risks associated with obesity and diabetes. The US Diabetes Prevention Program (DPP) validated that physical exercise significantly reduced the risk of developing diabetes and CVD was significantly reduced in the DPP and Diabetes Prevention Program Outcomes Study (DPPOS) study [8]. According to CDC, physical exercise not only reduced risk of developing diabetes and CVD but also helped to reduce body weight and even reduced the risk of developing certain cancers [9]. In addition, exercise also strengthen bones and muscles, improves mental health, daily activity, prevent falling by increasing balance. In combination with dietary changes, exercise can increase life expectancy irrespective of age, ethnicity, body shape, or body mass [9].
Corresponding author: Sabyasachi Sen (D) https://orcid.org/0000-0002-3675-9129 Division of Endocrinology, Department of Medicine, The George Washington University, 2300 Eye Street, NW, Washington, DC 20052, USA

E-mail: ssen1@gwu.edu

Received: Sep. 21, 2019; Accepted: Nov. 17, 2019
This is an Open Access article distributed under the terms of the Creative Commons Attribution Non-Commercial License (http://creativecommons.org/licenses/by-nc/4.0/) which permits unrestricted non-commercial use, distribution, and reproduction in any medium, provided the original work is properly cited. 
It is important to ascertain ideal biomarkers to detect the effect of both exercise and diabetes medications. The effect of exercise has been studied extensively using body composition parameters such as muscle mass, fat mass, weight, physical fitness (cardiovascular capacity, strength, agility, flexibility), heart rate, and blood pressure [10]. Currently, the standard practice for monitoring effect of exercise is by analyzing plasma or serum biochemistry. However, it may be more informative to study cells rather than plasma to observe effect at a cellular level, using adult stem cells (ASCs).

\section{WHY ADULT STEM CELLS}

Stem cells are nonspecialized cells which can differentiate into specialized tissue specific cells which subsequently leads to organ development. Predominantly, stem cells are divided into embryonic and somatic or ASCs. The roles of stem cells on embryonic development has remained as the main focus in regenerative medicine for long time compared to ASCs. ASCs can be found in different tissue including bone marrow, peripheral blood, blood vessels, skeletal muscle, adipose tissue, brain and many other tissues by forming a niche for specific and multi-tasking activities. For endothelial progenitor cells (EPCs) and mesenchymal stromal cells (MSCs), bone marrow is the main reservoir. Peripheral blood contain approximately $1 \%$ of mononuclear cells (MNCs) as EPCs. MSCs obtained from bone marrow and adipose tissue has also been well established for MSC production [11]. Predominantly, ASCs are responsible for daily tissue or cell maintenance, remodeling and regeneration of multiple tissues and especially to replenish cell death from apoptosis [12]. Often, ASCs respond to tissue-specific signals by migrating to the proximity of the injury site. Exercise can influence these ASCs function including mobilization in response to a chemotactic factor and fate by altering extracellular matrix composition, and inflammation [13]. In addition, exercise has been shown to promote migratory capacity of stem cells.

\section{EFFECT OF EXERCISE ON ENDOTHELIAL PROGENITOR CELLS}

\section{Effects on endothelial progenitor cell}

Human EPCs are circulating progenitor cells, abundantly available in peripheral blood, bone marrow and umbilical cord. They are much more abundant in bone marrow than pe- ripheral blood. Most commonly, EPCs are defined by cell surface markers that are progenitor such CD34 or CD133 along with a endothelial cell mark such as vascular endothelial growth factor receptor 2 (VEGFR2) (also known as kinase domain receptor $[\mathrm{KDR}]$ ) such as $\mathrm{CD} 34+$ or $\mathrm{CD} 34+/ \mathrm{KDR}+$ or $\mathrm{CD} 34+/ \mathrm{KDR}+/ \mathrm{CD} 133+$. EPCs ideally defined as CD34 plus KDR positive cells, play an important role in angiogenesis and neovascularization, predominantly, by incorporation into the endothelium or by its paracrine properties that favor de novo vessel formation [14]. CVD and diabetes often leads to the vascular damage and EPCs play a vital role in repair and regeneration of blood vessels. The benefit of physical activity can be enhanced by healthy nutrition and both can synergistically help to prevent or reverse the outcome of poor CVD outcomes of diabetes [15].

Metabolic disorders like diabetes dramatically decrease EPC number and impair its function. On the other hand, it is well established that increase of EPC number and function is beneficial for both diabetes and CVD $[10,13]$.

Physical activity increases the production and increases circulating numbers of EPCs. Studies have showed that EPC production is partially dependent on nitric oxide $(\mathrm{NO})$ production which may be secondary to its antiapoptotic effect $[16,17]$. Similarly, it is also reported that exercise helps to reduce phosphoinositide 3-kinase mediated apoptosis which depends on NO [18].

Prostaglandin E1 (PGE1)-mediated upregulation of EPC is also linked to the improvement of EPC function and improved angiogenesis. [19]. Another study showed improvement of EPC number may be related and preceded by an increase in plasma VEGF. They showed in patients with CAD, exercise induce a short-term myocardial ischemia which increase EPC numbers, depending on of bio-availability VEGF [20]. In addition to this study, patients with chronic heart failure show increased EPC counts by increasing not only plasma VEGF but also stromal derived factor 1 (SDF-1) levels post exercise [21]. Rise of CD34+/VEGFR2+ cell number may be also influenced by alterations in oxidative stress [22-24].

Exercise not only increases number of EPCs but also improves function of EPCs. Sen et al. [25] showed a 6-week exercise program improves $\mathrm{CD} 34+$ cell function by increasing migration of EPCs in response to the chemotactic factor SDF- $1 \alpha$ which leads to enhanced vasculoneogenesis.

It is also reported that exercise substantially influenced SDF$1 \alpha$ levels (bioavailability) over time [26]. In addition, studies 
have showed atherosclerotic plaque decline in response to exercise [27]. It has been reported that supervised exercise training (SET) boosts the circulating EPC counts and reduces asymmetric dimethylarginine (ADMA) levels that leads to increased angiogenesis and improved endothelial function and decrease atherosclerosis. Therefore, cell mobilization induced by exercise and reduction of ADMA may serve as a physiologic mechanism repair for atherosclerosis [28-30].

In patients with hypertension, exercise reduces impairment of EPC, which promote neovascularization to heal injury as a result of chronic hypertension [31]. In an interesting review Wahl et al. [32] summarized the process of EPC function. They discussed, exercise promote mechanical stress to the tissue and vasculature where the mechanical force directly or indirectly regulates EPCs fate. Collectively, exercise promote release of growth factors and other molecules like interleukin-6 (IL-6) and NO which facilitate EPC differentiation and production from bone marrow and also helps to promote migration and homing in the hypoxic tissue to improve angiogenesis and vasculogenesis [32].

Expectedly, the benefit of exercise is time dependent. Duration of exercise directly impacts circulating EPCs numbers [20]. It has been reported that intensive and moderate exercise activity for 30 minutes, increase circulating EPC number but this outcome is not seen when time of exercise is reduced to 10 minutes [33] and that a maximal bout of exercise, stimulates a significant shift in CD34+ cells toward CD34+/KDR+ cells, in other words making a progenitor cell population, more endothelium-like.

\section{Age and maturity affects endothelial progenitor cells}

The CD34+/KDR+EPC numbers are two times higher in young population compared to older group at resting state. Pro-maturity states such as diabetes and prediabetes has shown to reduce number of EPCs [10,34]. Studies showed that exercise increased number of EPCs in middle age and older persons [23]. Exercise helps the increase in prediabetes and diabetes setting even in middle aged individuals [23-25]. Interestingly, one of the studies showed exercise increased number of EPCs independent of age group [24].

\section{Effect of novel diabetes medications on endothelial progenitor cells}

As mentioned above, EPCs can act as a cellular biomarker that is more reliable than serum based markers for estimating and following endothelial dysfunction in early T2DM patients. Thus, investigating EPCs could help develop a CVD risk estimation, post pharmacotherapeutics [20,33,34].

Dipeptidyl peptidase-4 (DPP-4) inhibitors, a popular class of antidiabetic medications, have been shown to achieve improved glycemic control by lowering glycosylated hemoglobin (HbA1c), without causing hypoglycemia, and are weight neutral [7-9]. Because DPP-4 degrades particular incretins, such as SDF-1 $\alpha$, its inhibition is also linked with a potential mechanism to prevent vascular diseases. However, there is limited data demonstrating the potential cardiovascular effects of these medications. Only a few studies using either sitagliptin or saxagliptin have shown an increase in EPCs, and thus potential cardiovascular benefits, with DPP-4 therapy.

Metformin has commonly been used as the first line pharmacologic agent for treating diabetes and pre-diabetes as per the ADA guidelines. Metformin improves glycemic control by decreasing hepatic glucose production, decreasing glucose absorption in the intestines and stomach, and increasing insulinmediated glucose uptake [7-9]. Metformin has been shown to have cardio-protective effects by increasing colony forming unit (CFU)-Hill's colonies in type 1 diabetes mellitus [10], and is known to also have cardio-protective properties in T2DM subjects [34].

The up-regulation of SDF- $1 \alpha$ and VEGF, both chemotactic factors, in serum increases mobilization and recruitment of EPCs in the face of acute ischemic injury for repair and regeneration [34], and it postulated that DPP-4 inhibitors may increase EPCs mobilization from the bone marrow via their role in increased SDF- $1 \alpha$ presence in serum.

Since poor viability and impaired function of EPCs in early diabetes will ultimately affect the repair and regeneration of the endothelium, a prompt intervention may help to reduce or reverse cardiovascular risk by improving EPCs survival and function above and beyond adequate glucose metabolism control.

We conducted a study [34] where saxagliptin a DPP-4 enzyme inhibitor, was added to metformin. We wanted to investigate whether the number, function and gene expression of peripheral blood derived CD34+ cells improved in T2DM patients, independent of glycemia improvements. In this 12 weeks, double-blind, randomized placebo-controlled trial, 42 subjects already taking metformin 1 to $2 \mathrm{~g}$ /day were randomized to placebo or saxagliptin $5 \mathrm{mg}$. Subjects aged 40 to 70 years with diabetes for $<10$ years, with no known CVD, body mass index 25 to $39.9 \mathrm{~kg} / \mathrm{m}^{2}$, HbAlc $6 \%$ to $9 \%$ were included. 
We evaluated EPCs number, function, surface markers and gene expression, in addition to arterial stiffness, blood biochemistries, resting energy expenditure, and body composition parameters. A mixed model regression to examine saxagliptin versus placebo, accounting for within subject autocorrelation, was done with SAS version 9.4 (SAS Institute Inc., Cary, NC, USA) $(P<0.05)$.

Although there was no significant increase in CD34+ cell number, $\mathrm{CD} 31+$ cells percentage $(\mathrm{CD} 31 /$ total $\mathrm{MNC} \times 100)$ increased. Saxagliptin receiving arm showed increased CD34+ migration (in response to SDF-1 $\alpha$ ) with a trend of higher colony formation count. MNCs cytometry showed higher percentage of C-X-C chemokine receptor type 4 (CXCR4, a receptor for SDF-1a) double positivity for both CD34 and CD31 positive cells, indicating a functional improvement. Gene expression analysis showed an upregulation in $\mathrm{CD} 34+$ cells for antioxidant superoxide dismutase 1 (SOD1) $(P<0.05)$ and a downregulation in CD34- cells for IL-6 $(P<0.01)$. For arterial stiffness, both augmentation index and systolic blood pressure measures went down in saxagliptin subjects $(P<0.05)$. We concluded that saxagliptin, a novel DPP-4 inhibitor when administered orally, in combination with metformin, can help improve cellular and biochemical parameters of endothelial function in early diabetes before macrovascular complications appear. We also established that CD34+ cells can act as a valuable biomarker [34].

\section{Effects of exercise on mesenchymal stromal cells}

MSCs are multipotent cells which can differentiate into osteoblasts, adipocytes, and chondrocytes. Sources of obtaining MSC vary from umbilical cord blood, bone marrow, adipose tissue, pancreatic islet, fetal liver to lung [35-38]. Often, MSCs are defined by specific markers such as CD44, CD73, CD90, CD105 but not CD31, CD34, CD45 [39].

Studies have showed that exercise may facilitate MSC migration by increasing IL- 6 and recruit stem cells in the site of injury [40]. It was reported that MSC secretome is responsible for hematopoietic stem and progenitor cells (HSPC) mobilization and proliferation and exercise induce homing of HSPCs to extramedullary sites [41].

Often, the effect of MSC transplantation increased with exercise. Shin et al. [42] showed treadmill exercise increased therapeutic MSC transplantation in traumatic brain injury in a rat model. It has also been reported that exercise increased the efficiency of MSC transplantation in cerebral ischemic rats by reducing apoptosis [43]. Another study showed that the stromal vascular fraction, a well-known mixed population enriched with MSCs, and exercise, together helps to improve pain in patient with knee osteoarthritis [44]. Another group of scientists reported, exercise facilitates MSC transplantation in idiopathic osteonecrosis of the femoral head by increasing vascularization in bone graft [45].

Exercise plays a vital role in differentiation of multipotent MSCs. It is reported that exercise promote bone differentiation in MSCs. Li et al. [46] indicate mechanical force increased osteogenic differentiation by increasing bone formation transcription genes such as RUNX2 and osteoclacin and at the same time, it is responsible for reduction of peroxisome proliferator-activated receptor gamma 2 (PPAR $\gamma$-2) and CCAAT/ enhancer binding protein $\alpha(\mathrm{C} / \mathrm{EBP} \alpha)$ which indicates reduced adipogenesis. The effect of exercise on osteogenesis was observed for bone marrow derived MSCs [47]. A study that we conducted showed, exercise promote osteogenic differentiation in veteran population post exercise. Interestingly, bone differentiation markers genes such as Runt-related transcription factor (RUNX2), alkaline phosphatase (ALPL), and osteocalcin (BGLAP) upregulated significantly which indicate osteogenic differentiation [48]. Cook and Genever [49], discussed how signaling pathways manipulate MSC differentiation. Both bone morphogenetic protein (BMP) and WNT signaling pathways play an important role on MSC differentiation. WNT signaling promote osteogenic differentiation by upregulating RUNX and inhibiting PPAR $\gamma$. On the other hand, BMPs activates osteogenic differentiation by activating RUNX (Fig. 1) [49].

Maredziak et al. [50] showed that exercise is increasing bone marrow derived MSC number. This group also reported elevated ALPL, osteopontin and osteocalcin in plasma which may indicate increased musculoskeletal function in mice [50]. It is reported that exercise promote activation and differentiation of skeletal muscle cells by promoting growth fractors such as insulin growth factor 1 (IGF-1), mast-cell growth factor (MGF), fibroblast growth factor (FGF), hepatocyte growth factor (HGF), IL-6, and signaling molecule NO [32]. It is also reported that exercise may improves cartilage repair followed MSC transplantation [51].

Similar to exercise, weight reducing diabetes medications may also alter MSC differentiation pathway. However, placebo matched studies to elucidate such effects are warranted. Therefore, MSC differentiation pathway away from adipogenesis and 


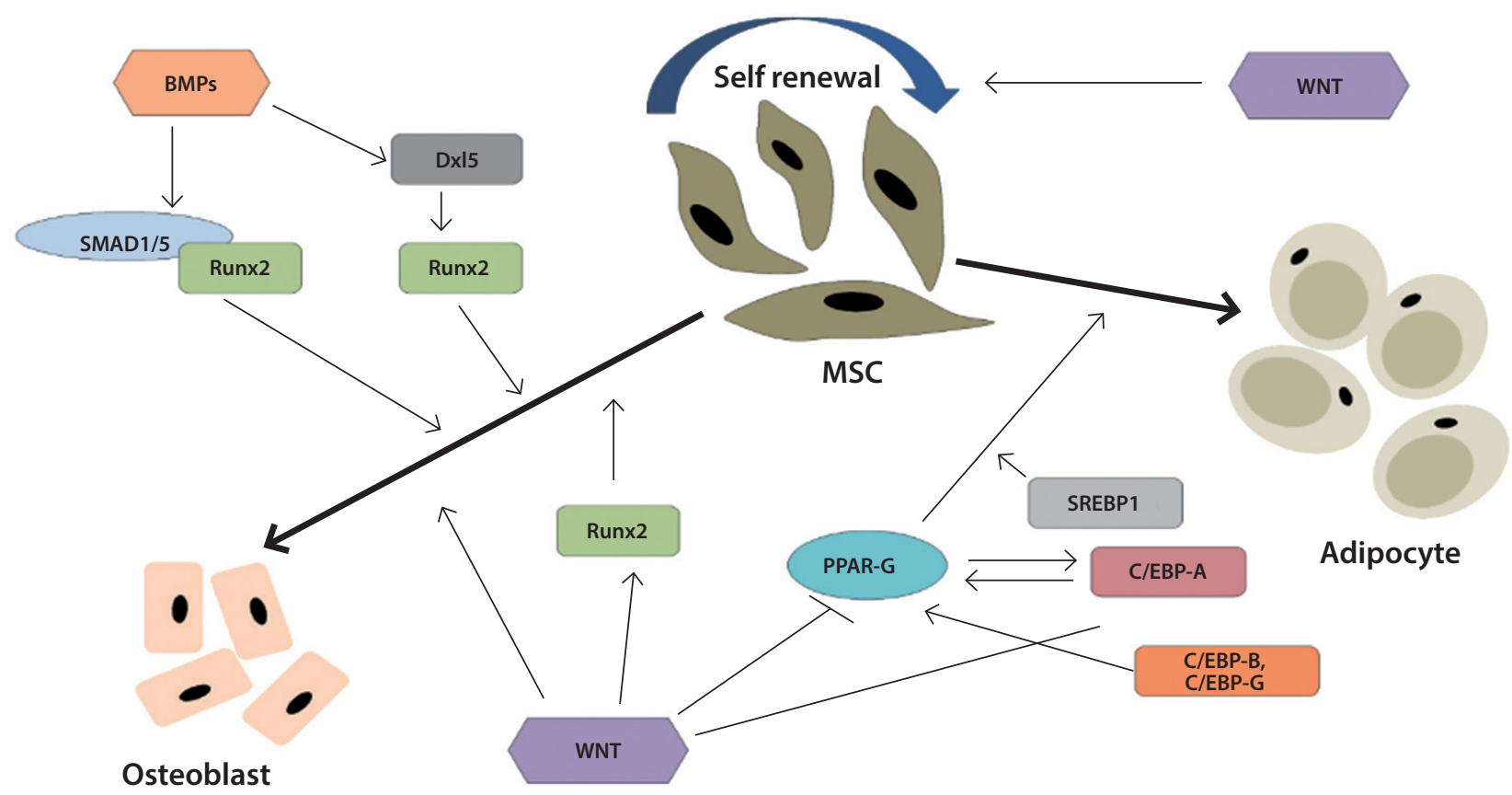

Fig. 1. Schematic representation of the role of bone morphogenetic proteins (BMPs) and Wnt on mesenchymal stromal cell (MSC) osteogenic and adipogenic differentiation. BMPs play vital role in osteogenic differentiation via Runt-related transcription factor 2 (RUNX2) whereas Wnt prevent adipogenesis by inhibiting peroxisome proliferator-activated receptor gamma (PPAR-G) and activating RUNX2. Adapted from Cook et al. [49], with permission from Springer Nature. Dxl5, distal less homeobox-5; SMAD1/5, Smads (or SMADs) comprise a family of structurally similar proteins that are the main signal transducers for receptors of the transforming growth factor beta (TGF-B) superfamily, which are critically important for regulating cell development and growth; SREBP1, sterol regulatory element-binding protein 1; C/EBP, CCAAT/enhancer binding protein.

towards osteogenesis may act as a useful biomarker to monitor effect of exercise and diabetes medications in subjects with diabetes. This may usher in assessing individual responses to exercise and diabetes medications.

\section{CONCLUSIONS}

Peripheral blood derived CD34+ progenitor cells and human fat derived MSCs are two adult progenitor/stem cells that can prove to be effective and efficient biomarkers, not only to monitor exercise but also to monitor response to diabetes medications. Both of these two biomarkers are easily obtainable from any adult person. This technology once perfected and standardized, can be a valuable cell based biomarker with predictability of future benefit or lack of it from an intervention in prediabetes, diabetes and obesity. It may also usher in an era of individualized medicine when metabolic dysfunction has been established to depend heavily on individual genetics, epigenetics, racial and ethnic differences.

\section{CONFLICTS OF INTEREST}

No potential conflict of interest relevant to this article was reported.

\section{ORCID}

Sabyasachi Sen https://orcid.org/0000-0002-3675-9129

\section{ACKNOWLEDGMENTS}

None

\section{REFERENCES}

1. National Institute of Diabetes and Digestive and Kidney Diseases: Overweight and obesity statistics, 2014. Available from: https://www.niddk.nih.gov/health-information/health-statistics/ overweight-obesity (cited 2019 Nov 20). 
2. World Health Organization: Diabetes fact sheet 2017. Available from: http://www.who.int/mediacentre/factsheets/fs312/en/ (cited 2019 Nov 20).

3. Centers for Disease Control and Prevention: High blood pressure facts 2016. Available from: https://www.cdc.gov/bloodpressure/ facts.htm (cited 2019 Nov 20).

4. Centers for Disease Control and Prevention: Stroke fact sheet 2017. Available from: https://www.cdc.gov/stroke/facts.htm (cited 2019 Nov 20).

5. Centers for Disease Control and Prevention: Heart disease fact 2017. Available from: https://www.cdc.gov/heartdisease/facts. htm (cited 2019 Nov 20).

6. Centers for Disease Control and Prevention: National diabetes statistics report 2017. Available from: https:/www.cdc.gov/diabetes/ data/statistics/statistics-report.html (cited 2019 Nov 20).

7. American Diabetes Association. Economic costs of diabetes in the U.S. in 2012. Diabetes Care 2013;36:1033-46.

8. Knowler WC, Barrett-Connor E, Fowler SE, Hamman RF, Lachin JM, Walker EA, Nathan DM; Diabetes Prevention Program Research Group. Reduction in the incidence of type 2 diabetes with lifestyle intervention or metformin. N Engl J Med 2002;346:393-403.

9. Kim MK, Ko SH, Kim BY, Kang ES, Noh J, Kim SK, Park SO, Hur KY, Chon S, Moon MK, Kim NH, Kim SY, Rhee SY, Lee KW, Kim JH, Rhee EJ, Chun S, Yu SH, Kim DJ, Kwon HS, Park KS; Committee of Clinical Practice Guidelines, Korean Diabetes Association. 2019 Clinical practice guidelines for type 2 diabetes mellitus in Korea. Diabetes Metab J 2019;43:398-406.

10. Kokkinos P, Narayan P. Cardiorespiratory fitness in cardiometabolic diseases. Cham: Springer Nature Publications; 2019. Chapter 4, Effect of exercise on adult stem cells; p49-56.

11. Hass R, Kasper C, Bohm S, Jacobs R. Different populations and sources of human mesenchymal stem cells (MSC): a comparison of adult and neonatal tissue-derived MSC. Cell Commun Signal 2011;9:12.

12. Yoder MC. Human endothelial progenitor cells. Cold Spring Harb Perspect Med 2012;2:a006692.

13. Van Craenenbroeck EM, Conraads VM. Endothelial progenitor cells in vascular health: focus on lifestyle. Microvasc Res 2010;79:184-92.

14. Boppart MD, De Lisio M, Witkowski S. Exercise and stem cells. Prog Mol Biol Transl Sci 2015;135:423-56.

15. Francois ME, Pistawka KJ, Halperin FA, Little JP. Cardiovascular benefits of combined interval training and post-exercise nutrition in type 2 diabetes. J Diabetes Complications 2018;32:
226-33.

16. Laufs U, Werner N, Link A, Endres M, Wassmann S, Jurgens K, Miche E, Bohm M, Nickenig G. Physical training increases endothelial progenitor cells, inhibits neointima formation, and enhances angiogenesis. Circulation 2004;109:220-6.

17. Steiner S, Niessner A, Ziegler S, Richter B, Seidinger D, Pleiner J, Penka M, Wolzt M, Huber K, Wojta J, Minar E, Kopp CW. Endurance training increases the number of endothelial progenitor cells in patients with cardiovascular risk and coronary artery disease. Atherosclerosis 2005;181:305-10.

18. Jenkins NT, Witkowski S, Spangenburg EE, Hagberg JM. Effects of acute and chronic endurance exercise on intracellular nitric oxide in putative endothelial progenitor cells: role of NAPDH oxidase. Am J Physiol Heart Circ Physiol 2009;297:H1798805.

19. Gensch C, Clever Y, Werner C, Hanhoun M, Bohm M, Laufs U. Regulation of endothelial progenitor cells by prostaglandin E1 via inhibition of apoptosis. J Mol Cell Cardiol 2007;42:670-7.

20. Adams V, Lenk K, Linke A, Lenz D, Erbs S, Sandri M, Tarnok A, Gielen S, Emmrich F, Schuler G, Hambrecht R. Increase of circulating endothelial progenitor cells in patients with coronary artery disease after exercise-induced ischemia. Arterioscler Thromb Vasc Biol 2004;24:684-90.

21. Sarto P, Balducci E, Balconi G, Fiordaliso F, Merlo L, Tuzzato G, Pappagallo GL, Frigato N, Zanocco A, Forestieri C, Azzarello G, Mazzucco A, Valenti MT, Alborino F, Noventa D, Vinante O, Pascotto P, Sartore S, Dejana E, Latini R. Effects of exercise training on endothelial progenitor cells in patients with chronic heart failure. J Card Fail 2007;13:701-8.

22. Witkowski S, Lockard MM, Jenkins NT, Obisesan TO, Spangenburg EE, Hagberg JM. Relationship between circulating progenitor cells, vascular function and oxidative stress with long-term training and short-term detraining in older men. Clin Sci (Lond) 2010;118:303-11.

23. Hoetzer GL, Van Guilder GP, Irmiger HM, Keith RS, Stauffer BL, DeSouza CA. Aging, exercise, and endothelial progenitor cell clonogenic and migratory capacity in men. J Appl Physiol (1985) 2007;102:847-52.

24. Thijssen DH, Vos JB, Verseyden C, van Zonneveld AJ, Smits P, Sweep FC, Hopman MT, de Boer HC. Haematopoietic stem cells and endothelial progenitor cells in healthy men: effect of aging and training. Aging Cell 2006;5:495-503.

25. Sen S, Witkowski S, Lagoy A, Islam AM. A six-week home exercise program improves endothelial function and CD34+ circulating progenitor cells in patients with pre-diabetes. J Endo- 
crinol Metab 2015;5:163-71.

26. Van Craenenbroeck EM, Bruyndonckx L, Van Berckelaer C, Hoymans VY, Vrints CJ, Conraads VM. The effect of acute exercise on endothelial progenitor cells is attenuated in chronic heart failure. Eur J Appl Physiol 2011;111:2375-9.

27. Ajijola OA, Dong C, Herderick EE, Ma Q, Goldschmidt-Clermont PJ, Yan Z. Voluntary running suppresses proinflammatory cytokines and bone marrow endothelial progenitor cell levels in apolipoprotein-E-deficient mice. Antioxid Redox Signal 2009;11:15-23.

28. Schlager O, Giurgea A, Schuhfried O, Seidinger D, Hammer A, Groger M, Fialka-Moser V, Gschwandtner M, Koppensteiner R, Steiner S. Exercise training increases endothelial progenitor cells and decreases asymmetric dimethylarginine in peripheral arterial disease: a randomized controlled trial. Atherosclerosis 2011;217:240-8.

29. Van Craenenbroeck EM, Beckers PJ, Possemiers NM, Wuyts K, Frederix G, Hoymans VY, Wuyts F, Paelinck BP, Vrints CJ, Conraads VM. Exercise acutely reverses dysfunction of circulating angiogenic cells in chronic heart failure. Eur Heart J 2010;31:1924-34.

30. Rehman J, Li J, Parvathaneni L, Karlsson G, Panchal VR, Temm CJ, Mahenthiran J, March KL. Exercise acutely increases circulating endothelial progenitor cells and monocyte-/macrophage-derived angiogenic cells. J Am Coll Cardiol 2004;43: 2314-8.

31. Fernandes T, Nakamuta JS, Magalhaes FC, Roque FR, LaviniRamos C, Schettert IT, Coelho V, Krieger JE, Oliveira EM. Exercise training restores the endothelial progenitor cells number and function in hypertension: implications for angiogenesis. J Hypertens 2012;30:2133-43.

32. Wahl P, Brixius K, Bloch W. Exercise-induced stem cell activation and its implication for cardiovascular and skeletal muscle regeneration. Minim Invasive Ther Allied Technol 2008;17:919.

33. Laufs U, Urhausen A, Werner N, Scharhag J, Heitz A, Kissner G, Bohm M, Kindermann W, Nickenig G. Running exercise of different duration and intensity: effect on endothelial progenitor cells in healthy subjects. Eur J Cardiovasc Prev Rehabil 2005;12:407-14.

34. Dore FJ, Domingues CC, Ahmadi N, Kundu N, Kropotova Y, Houston S, Rouphael C, Mammadova A, Witkin L, Khiyami A, Amdur RL, Sen S. The synergistic effects of saxagliptin and metformin on CD34+ endothelial progenitor cells in early type 2 diabetes patients: a randomized clinical trial. Cardiovasc Dia- betol 2018;17:65.

35. Zuk PA, Zhu M, Mizuno H, Huang J, Futrell JW, Katz AJ, Benhaim P, Lorenz HP, Hedrick MH. Multilineage cells from human adipose tissue: implications for cell-based therapies. Tissue Eng 2001;7:211-28.

36. Zanini C, Bruno S, Mandili G, Baci D, Cerutti F, Cenacchi G, Izzi L, Camussi G, Forni M. Differentiation of mesenchymal stem cells derived from pancreatic islets and bone marrow into islet-like cell phenotype. PLoS One 2011;6:e28175.

37. Stagg J, Galipeau J. Mechanisms of immune modulation by mesenchymal stromal cells and clinical translation. Curr Mol Med 2013;13:856-67.

38. Jamal F. Genetic engineering: an insight into the strategies and applications. London: InTech; 2016. Chapter 5, Genetic modification of stem cells in diabetes and obesity; p. 75-84.

39. Dominici M, Le Blanc K, Mueller I, Slaper-Cortenbach I, Marini F, Krause D, Deans R, Keating A, Prockop Dj, Horwitz E. Minimal criteria for defining multipotent mesenchymal stromal cells. The International Society for Cellular Therapy position statement. Cytotherapy 2006;8:315-7.

40. Schmidt A, Bierwirth S, Weber S, Platen P, Schinkothe T, Bloch W. Short intensive exercise increases the migratory activity of mesenchymal stem cells. Br J Sports Med 2009;43:195-8.

41. Emmons R, Niemiro GM, Owolabi O, De Lisio M. Acute exercise mobilizes hematopoietic stem and progenitor cells and alters the mesenchymal stromal cell secretome. J Appl Physiol (1985) 2016;120:624-32.

42. Shin MS, Park HK, Kim TW, Ji ES, Lee JM, Choi HS, Kim MY, Kim YP. Neuroprotective effects of bone marrow stromal cell transplantation in combination with treadmill exercise following traumatic brain injury. Int Neurourol J 2016;20(Suppl 1): S49-56.

43. Zhang YX, Yuan MZ, Cheng L, Lin LZ, Du HW, Chen RH, Liu $\mathrm{N}$. Treadmill exercise enhances therapeutic potency of transplanted bone mesenchymal stem cells in cerebral ischemic rats via anti-apoptotic effects. BMC Neurosci 2015;16:56.

44. Gibbs N, Diamond R, Sekyere EO, Thomas WD. Management of knee osteoarthritis by combined stromal vascular fraction cell therapy, platelet-rich plasma, and musculoskeletal exercises: a case series. J Pain Res 2015;8:799-806.

45. Aoyama T, Fujita Y, Madoba K, Nankaku M, Yamada M, Tomita M, Goto K, Ikeguchi R, Kakinoki R, Matsuda S, Nakamura T, Toguchida J. Rehabilitation program after mesenchymal stromal cell transplantation augmented by vascularized bone grafts for idiopathic osteonecrosis of the femoral head: a pre- 
liminary study. Arch Phys Med Rehabil 2015;96:532-9.

46. Li R, Liang L, Dou Y, Huang Z, Mo H, Wang Y, Yu B. Mechanical strain regulates osteogenic and adipogenic differentiation of bone marrow mesenchymal stem cells. Biomed Res Int 2015; 2015:873251.

47. Liu SY, He YB, Deng SY, Zhu WT, Xu SY, Ni GX. Exercise affects biological characteristics of mesenchymal stromal cells derived from bone marrow and adipose tissue. Int Orthop 2017;41:1199-209.

48. Kundu N, Domingues CC, Nylen ES, Paal E, Kokkinos P, Sen S. Endothelium-derived factors influence differentiation of fatderived stromal cells post-exercise in subjects with prediabetes.
Metab Syndr Relat Disord 2019;17:314-22.

49. Cook D, Genever P. Regulation of mesenchymal stem cell differentiation. Adv Exp Med Biol 2013;786:213-29.

50. Maredziak M, Smieszek A, Chrząstek K, Basinska K, Marycz K. Physical activity increases the total number of bone-marrowderived mesenchymal stem cells, enhances their osteogenic potential, and inhibits their adipogenic properties. Stem Cells Int 2015;2015:379093.

51. Yamaguchi S, Aoyama T, Ito A, Nagai M, Iijima H, Tajino J, Zhang X, Kiyan W, Kuroki H. The effect of exercise on the early stages of mesenchymal stromal cell-induced cartilage repair in a rat osteochondral defect model. PLoS One 2016;11:e0151580. 